$$
\begin{aligned}
& \text { 震 }
\end{aligned}
$$

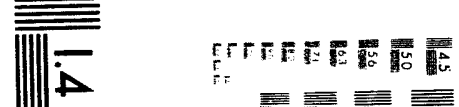

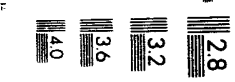

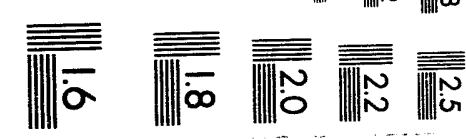



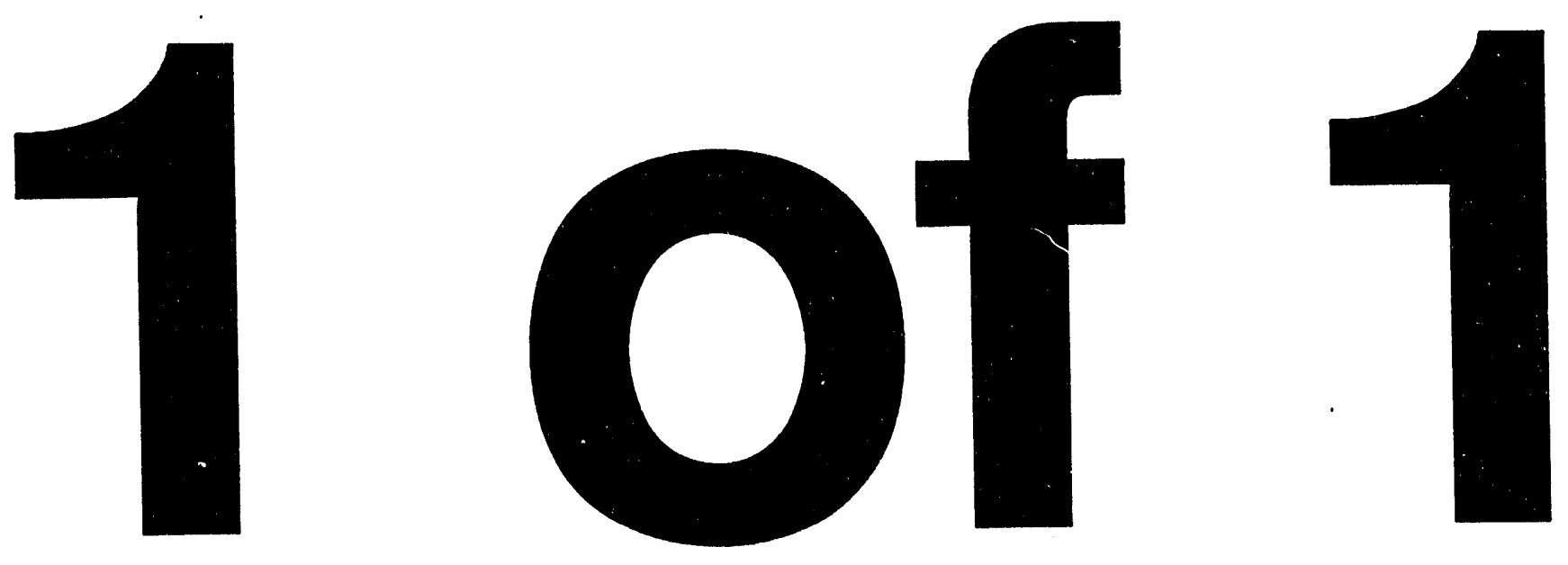


\title{
SANDD.93-1764C
}

\section{PERFORMANCE OF AN INDUCTION COIL LAUNCHER}

\author{
I. R. Shokair, M. Cowan, R. J. Kaye and B. M. Marder
}

Con $940481-4$

Sandia National Laboratories

Beam, Plasma, and Electromagnetic Theory Department

\author{
P. O. Box 5800
}

Albuquerque, New Mexico 87185-1186

\begin{abstract}
Performance of an electromagnetic induction launcher is considered for three types of armatures. These are: Solid, 1-element wound and 16-element wound aluminum armatures. The one element wound armature has uniform current density throughout. Because of the uniformity of the current density, the wound armature can withstand field reversal (working against embedded flux in the armature) and still maintain low temperature. Slingshot simulations were performed for several configurations. Best performance was obtained for a single element wound armature with two field reversals. For a $60 \mathrm{~kg}$ projectile, $10.5 \mathrm{~cm}$ coil inner radius and 5.5 $\mathrm{cm}$ coil build, the velocity after 50 meters of launcher length ( 670 stages) exceeded $3.5 \mathrm{~km} / \mathrm{sec}$ with an overall efficiency of about $45 \%$. For the same parameters the solid and 16 element wound armatures reach a velocity of about $3.3 \mathrm{~km} / \mathrm{sec}$ after 800 stages $(60$ meters of launcher length) but without field reversal. A velocity of $3.5 \mathrm{~km} / \mathrm{sec}$ is possible after 60 meters of launcher length with the 16-element wound armature with one field reversal, but the temperature is close to the melting temperature of aluminum. In all simulations with a solid armature, melting of some of the surface material occurs. However, it is shown that most of the melting occurs after contribution has been made to the forward going pressure, that is, melting does not affect the electrical performance of the launcher. The effect of coil firing time jitter on launcher performance is also considered and is found to be very small for realistic perturbations. For $\pm 2 \mu$-secs random jitter, the reduction in the final velocity for a 60 meter launcher with a solid armature is less than $0.1 \%$ and the increase in temperature is only $2 \%$. This result holds for all types of armatures.
\end{abstract}

\section{Introduction}

The electromagnetic induction launcher accelerates a conducting armature by inducing armature current opposite to coil currents. The armature current is induced in an attempt to conserve magnetic flux in the armature. The interaction of the net radial magnetic field with the azimuthal armature current results in an axial force that accelerates the armature ${ }^{(1-2)}$. If the launcher geometry, the coil firing times and current rise lengths are adjusted properly, a near constant acceleration can be maintained. A snapshot of coils, armature and magnetic field lines for a typical induction launcher is shown in Fig. (1).

Because of the finite resistivity the armature current decays and the magnetic field diffuses into the armature. For a solid armature, if the firing position of the coils is advanced (slipped) to account for field diffusion, near constant axial acceleration can be maintained ${ }^{(3)}$. For a 1 -element wound armature ${ }^{(4)}$, no slipping is needed, but there is still field diffusion due to the finite resistivity resulting in an $L / R$ decay of the $-1-$ 
acceleration. A multiple element wound armature with many elements behaves in a very similar way to a solid armature with the exception that the current is distributed uniformly in the radial direction, thus advancing of the firing position is needed for this type of armature as in a solid armature.

Because of finite resistivity, induced armature currents decay resulting in field diffusion into the armature. After a period of time of the order of the $L / R$ decay time has elapsed, the armature is embedded with flux (field) with little current. If at this point in time the coil voltage is reversed, the armature will attempt to maintain its original flux, thus inducing an opposite current which has roughly twice the magnitude of the original armature current. Thus the axial force between coil and armature and therefore the efficiency is roughly doubled. For the solid and multiple element wound armatures the coil firing times have to be retarded in such a way so that the generated axial force is uni-directional throughout the length of the armature. The retardation distance is roughly the same as the amount of slipping done before the field reversal. Since very high currents are induced ( $\sim$ twice the current without reversal) and the local Ohmic heat generation is proportional to the square of the current density, it is expected that field reversal will be practical only for wound armatures in which the current is distributed radially over regions much thicker than a skin depth because of temperature rise considerations. For wound armatures the limit on temperature rise will most likely be set by the type of insulation used rather than the conductor melting temperature.

In this paper we consider the performance of a certain launcher for the three types of armatures mentioned above. This is done via Slingshot ${ }^{(5)}$ simulations. For the simulations the following parameters are used: Projectile mass $=60 \mathrm{~kg}$, armature: length $=40 \mathrm{~cm}, I R=5.5 \mathrm{~cm}$ and $O R=9.5 \mathrm{~cm}$, Coils: width $=6 \mathrm{~cm}$, center to center spacing $=7.5 \mathrm{~cm}, \mathbb{R}=10.5 \mathrm{~cm}, \mathrm{OR}=16.0$ (fill factor 0.5 ) or $18.5 \mathrm{~cm}$ (fill factor 0.2 ), Voltage = $40 \mathrm{kV}$, and $\mathrm{C}=1600 \mu \mathrm{F} \rightarrow \mathrm{E}=1.28 \mathrm{MJ} /$ stage. Initial temperature of coils and armature $=20^{\circ} \mathrm{C}$. Number of stages $=800$ and all stages crowbarred at peak current. Number of turns in each coil is determined by projectile velocity except first 3 coils have 100 turns. Initial velocity $=10 \mathrm{~m} / \mathrm{sec}$ The coil circuits and parameters are shown in Fig. (2).

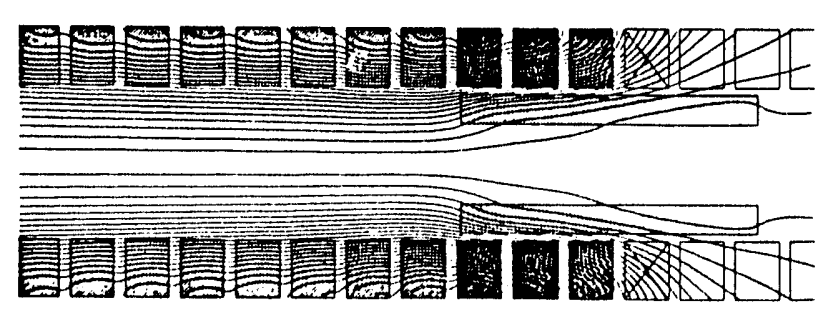

Fig. 1. Snapshot of induction launcher and field lines. The armature is moving to the right and coil marked with an $\mathrm{X}$ has just fired. Current is proportional to shading density

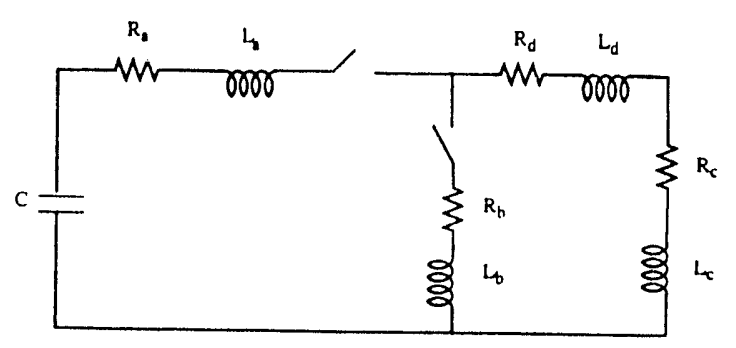

Fig.2. Circuit diagram for a typical coil. $R_{\alpha}=1 \mathrm{~m} \Omega, R_{b}=25 \mathrm{~m} \Omega, R_{d}=1 \mathrm{~m} \Omega$ $L_{\mu}=0.1 \mu \mathrm{H}, \mathrm{L}_{\mathrm{b}}=2.5 \mu \mathrm{H}, \mathrm{L}_{\mathrm{d}}=0.1 \mu \mathrm{H}$ 
Other parameters will be noted for the specific simulation. In all simulations the coil firing is based on armature position, namely a coil is energized when the condition $Z_{c}-Z_{a} \leq Z_{\text {slip }}+Z_{r i s c}$ is satisfied, where $Z_{c}$ is the position of the coil center, $Z_{a}$ is the armature position (rear), $Z_{\text {slip }}$ is the slip distance and $Z_{\text {rise }}$ is the coil rise length, that is armature velocity times the coil current rise time. In the code, the number of turns is determined based on the rise length which is input for all the stages. In several of the simulations an attempt has been made to optimize the results in terms of maximizing the output velocity and minimizing the peak temperature. This is done by variation of the slip speed, rise length and in cases with field reversal, the retardation of firing positions and locations of field reversal. Since the launcher system output is an integral over all the stages, local optimization of a stage or a group of stages does not imply global optimization. In fact, early optimization of slip speed for example can result in good performance for early stages, but rapid deterioration of performance for later stages with a lower overall efficiency. In many cases the optimization process turns out to be one of trial and error and can involve many iterations. Simulations and results are discussed in detail in sections II-IV for the three types of armatures.

In actual experiments of electromagnetic launch, there are uncertainties associated with coil firing times and measured armature position. With a fixed uncertainty in the firing time, the error in firing position is proportional to armature speed. Thus it is important to estimate the effects of such uncertainties on the overall launcher performance. This is considered in some detail in section V. In section VI the results are summarized.

\section{Simulations with a Solid Armature}

We first consider simulations with a solid aluminum armature. This type of armature is the simplest and has the advantage of being able to maintain nearly constant acceleration by using an appropriate slip speed. The disadvantage of this type of armature is clearly the fact that current only penetrates a thickness on the order of a skin depth, resulting in very large current densities and excessive localized heating.

The first simulation considered is for the previously listed parameters and using proportional slip, that is the

slip distance $=\alpha Z_{p}$, where $\alpha$ is a constant and $Z_{p}$ is the armature position. The value $\alpha=4.17 \times 10^{-3}$ is used and amounts to a total slip of $25 \mathrm{~cm}$ for the 60 meter long launcher. This amount added to the rise length of $15 \mathrm{~cm}$ is the total armature length. This choice for slip is reasonable (but not necessarily optimum) since it conserves slip during the early stages of acceleration. Faster slip improves performance early on, but as field slips out of the armature, performance deteriorates. This is the case because the natural field diffusion speed is larger than the slip speed used. With this value of $\alpha$, coil build of $5.5 \mathrm{~cm}$ and fill factor of 0.5 , the velocity reached $3124 \mathrm{~m} / \mathrm{sec}$ and the temperature reached $971^{\circ} \mathrm{C}$ after 60 meters of gun length and after muzzle braking the temperature reached $1128^{\circ} \mathrm{C}$ which is clearly above the melting temperature of aluminum. The average forward going pressure (total axial force divided by the armature cross sectional area) iollows the acceleration, and ranges between 1.4 and $2.4 \mathrm{kBars}$. As will be discussed later, better resolution of a skin depth results in 
significantly higher temperatures but with no change in performance. The results of this simulation are shown in Fig. (3).

The cause of the spikes in the acceleration curve is due to the fact that the number of turns in the coils is arbitrarily restricted to integer values, which is determined by the code based on the rise length. Because of the integer number of turns the actual rise length is discontinuous, giving rise to mismatches in currents and thus the jumps in acceleration. If the number of turns is unrestricted, the acceleration curve is smoothed. In practice, a near constant rise length can be obtained by using either fractional turns (with multiple feeds such coils can be made nearly axisymmetric), or through periodic adjustment of the capacitance. With unrestricted number of turns, the final velocity reached $3188 \mathrm{~m} / \mathrm{sec}$ and the maximum temperature reached $879^{\circ} \mathrm{C}$ after muzzle braking. If the slip factor $\alpha$ is increased to $5 \times 10^{-3}$, the final velocity is $3286 \mathrm{~m} / \mathrm{sec}$ and the maximum temperature reaches $842^{\circ} \mathrm{C}$. If the slip is changed to a constant slip speed of $7.0 \mathrm{~m} / \mathrm{sec}$, simulation of the same parameters gives a final velocity of $3155 \mathrm{~m} / \mathrm{sec}$ and $\mathrm{T}=887^{\circ} \mathrm{C}$.
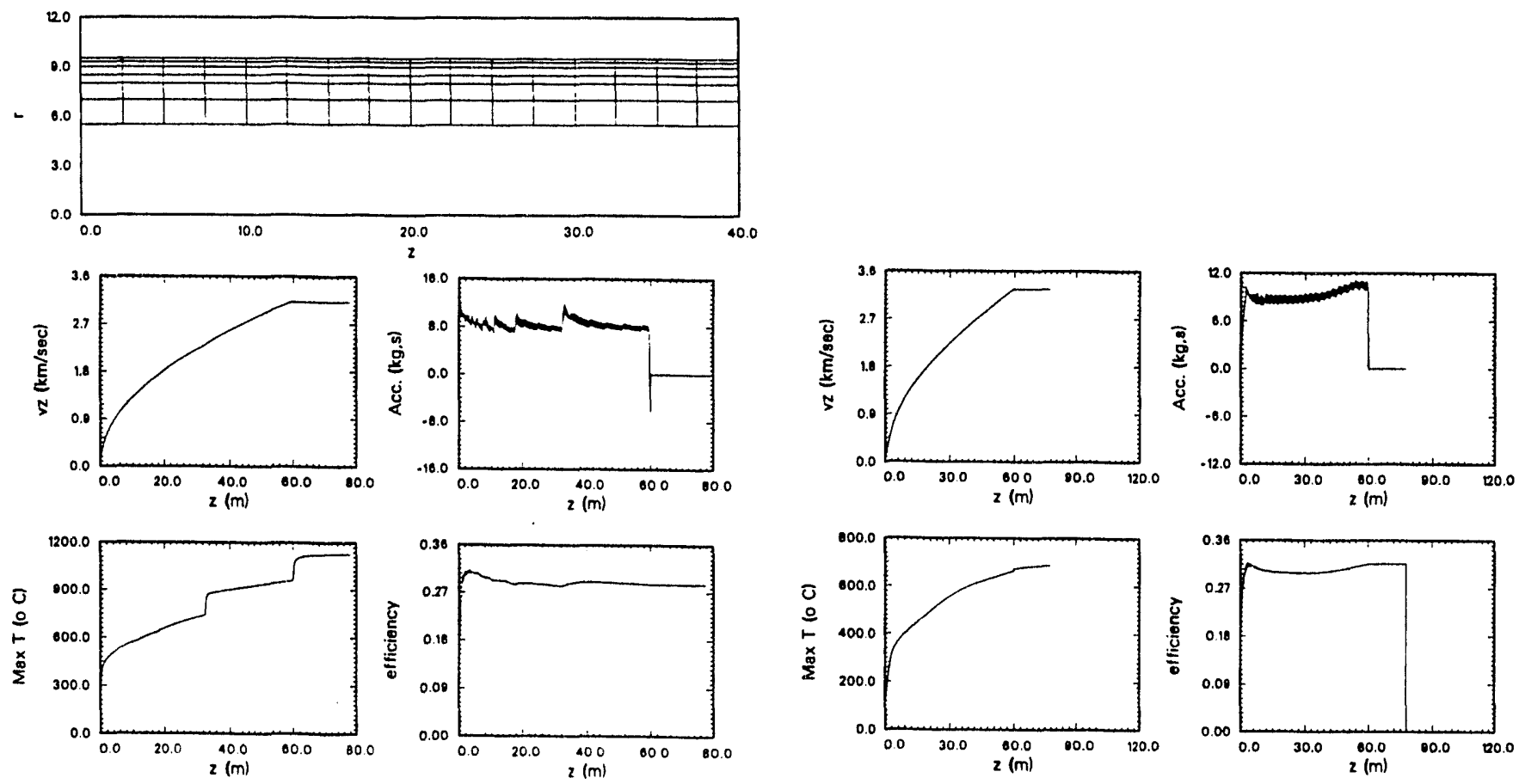

Fig. 3. Armature zoning and performance results for an 800 stage launcher and number of turns restricted to integer values.
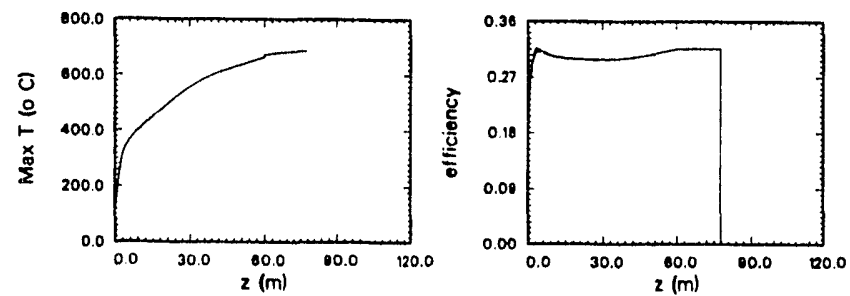

Fig. 4. Performance of an 800 stage launcher with unrestricted number of turns and energy grading for the first 30 stages. Slip constant $=5 \times 10^{-3}$ and rise length $=15 \mathrm{~cm}$.

The temperature rise in the above simulations is clearly unacceptable. A significant fraction of the temperature rise occurs during the first few stages of acceleration. This is because of the high current (with no initial flux) and the relatively long time for which this current persists. If the energy is graded for the first few stages, before significant slip has occurred, it is possible to build up the full armature flux gradually with low current. Since the Ohmic heating is proportional to the square of the current this is expected to result in temperature reduction, of course with some loss in kinetic energy gain. Figure (4) shows results of a simulation in which the energy of the first 30 stages is graded nearly linearly. The velocity at 60 meters reached $3258 \mathrm{~m} /$ 
sec and the temperature is $671^{\circ} \mathrm{C}$. After muzzle braking the velocity is unchanged and the temperature reaches $686^{\circ} \mathrm{C}$. With further adjustments we expect that this temperature rise can be reduced to below the melting point of aluminum, but since a skin depth is not well resolved by armature zoning, the actual highest temperature is expected to be above melting.

With the coil build changed to $8.0 \mathrm{~cm}$ with 0.2 fill factor and with the same energy grading and other parameters unchanged, we find the velocity reaches $3019 \mathrm{~m} / \mathrm{sec}$ and the temperature is $523^{\circ} \mathrm{C}$ at 60 meters, reaching a maximum of $533^{\circ} \mathrm{C}$ after muzzle braking. To increase the velocity, the energy in a stage can be increased, but this will result in larger stresses and higher armature temperatures.

In the Slingshot code the armature is divided into several elements in order to resolve the current distribution both radially and axially. For the simulations shown, the armature is divided into 96 elements: 16 in the axial direction, each $2.5 \mathrm{~cm}$ long, and 6 in the radial direction of thicknesses 2, 3, 5, 5, 10 and $15 \mathrm{~mm}$ as shown in Fig. (3). The outer surface elements are $2 \mathrm{~mm}$ thick, which is sufficiently thin to give the correct value of the total current within an element and thus the correct force on the armature. However, this thickness is of the order of a skin depth and thus the radial current profile and therefore the temperature rise are not well resolved. Since the rise length is fixed at $l_{r}=15 \mathrm{~cm}$, the skin depth can be written approximately in terms of the axial velocity $v_{z}$ as:

$\delta=\sqrt{\frac{2}{\mu_{o} \sigma \omega}}=\sqrt{\frac{4 l_{r}}{\pi \mu_{o} \sigma v_{z}}}$

where $\sigma$ is the conductivity. In the above equation we assumed that the frequency can be approximated by: $\omega=\pi /\left(2 t_{r}\right)$ where $t_{r}$ is the coil current rise time which for a fixed rise length is: $t_{r}=l_{r} / v_{z}$. For the 7075T73 aluminum armature at $20^{\circ} \mathrm{C}$ and for $v_{z}=1000 \mathrm{~m} / \mathrm{sec}$, the skin depth is roughly $\delta=2.5 \mathrm{~mm}$. If the Slingshot code predicts the correct total current in an element and if we assune that the current radial profile is exponential with the decay length equal to a skin depth, we find the true temperature rise is:

$$
\Delta T=\frac{\alpha_{0}}{\alpha^{\prime}}\left[\left(\frac{\alpha^{\prime}}{\alpha_{0}} \Delta T_{s}+1\right)^{R}-1\right], \quad R=\frac{(\Delta r)^{2}}{\delta^{2}\left(1-e^{-(\Delta r) / \delta}\right)^{2}},
$$

where $\Delta r$ is the radial thickness of the element, $\delta$ is the skin depth, $\Delta T_{s}$ is the Slingshot temperature rise, and we further assumed that the resistivity divided by the product of the heat capacity and density is linearly dependent on temperature as: $\eta /\left(\rho C_{v}\right)=\alpha_{0}+\alpha^{\prime}\left(T-T_{0}\right)$. For the above simulation with $5.5 \mathrm{~cm}$ coil build, with energy grading and $\Delta T_{s}=666^{\circ} \mathrm{C}$ (final temperature of $686^{\circ} \mathrm{C}$ ) and for $\mathrm{R}=2.1$, (result for $\Delta r=2$ $\mathrm{mm}$ and $\delta=2.5 \mathrm{~mm}$ ) we find $\Delta T=2331^{\circ} \mathrm{C}$, clearly far beyond the melting temperature. 
Because of the high temperature gradients involved it is likely that thermal conduction will have some effect on armature temperature rise. A simple 1-D finite element algorithm was written and incorporated into Slingshot to estimate the effect of thermal conduction in the radial direction ${ }^{(6)}$. This is done be integrating the heat conduction equation over the volume of the armature elements which gives:

$\rho C_{v} \delta V_{i} \partial T_{i}=Q_{o} \delta V_{i}-\int_{\delta S_{i}} d \vec{S} \bullet \vec{q}$

where $T_{i}$ is the average temperature, $\delta V_{i}$ is the volume and $\delta S_{i}$ is the surface area of the $i$ 'th element. $Q_{0}$ is the volumetric heat source $\left(Q_{0}=\eta j^{2}\right)$ and $\vec{q}$ is the heat flux given by $\vec{q}=-\kappa \nabla T$, where $\kappa$ is the thermal conductivity. Since the radial temperature gradient is much larger than the axial gradient, we only consider conduction in the radial direction. This results in an equation for the time rate of change of the temperature for the i'th element given by:

$\frac{d T_{i}}{d t}=\frac{Q_{o}}{\rho C_{v}}-\sum_{j} \frac{\kappa}{\rho C_{\nu}}\left\{\frac{\delta z_{i j}}{\delta z_{i}}\right\}\left\{\frac{\left|r_{i j}\right|}{\bar{r}_{i} \delta r_{i}}\right\}\left\{\frac{T_{i}-T_{j}}{\left|\bar{r}_{i}-\bar{r}_{j}\right|}\right\}$

where the sum is over elements that are in contact with the $i$ 'th element, $r_{i j}$ is the radius at which the elements $i$ and $j$ are in contact, $\bar{r}_{i}$ is the average radius of $i$ 'th element, $\delta z_{i}$ is the axial extent of $i$ 'th element and $\delta z_{i j}$ is the length of $j$ 'th element that is in contact with the $i$ 'th element. Solution of the above equation is by normal finite differencing over the time variable as is done for the Slingshot circuit equations. To better represent the radial current profile and temperature gradient we ran a Slingshot simulation of the above parameters (with $5.5 \mathrm{~cm}$ coil build, energy grading and proportional slip with $\alpha=5 \times 10^{-3}$ ) and with finer armature zoning (radial region thicknesses are: $1,1.5,2.5,5,5,10$ and $15 \mathrm{~mm}$ ) with and without thermal conduction. The final velocity was only slightly changed $(3249 \mathrm{~m} / \mathrm{sec}$ without conduction and $3248 \mathrm{~m} / \mathrm{sec}$ with conduction compared to 3258 with coarse zoning and no conduction), but the temperature changed significantly $\left(1580^{\circ} \mathrm{C}\right.$ without and 1145 ${ }^{\circ} \mathrm{C}$ with conduction compared to $686^{\circ} \mathrm{C}$ ). For the case with thermal conduction the temperature quoted is the maximum temperature (at 60 meters).

The bottom line result is that a room temperature solid aluminum armature $(40 \mathrm{~cm}$ long and $9.5 \mathrm{~cm}$ outer radius and $5.5 \mathrm{~cm}$ inner radius) with a total mass of $60 \mathrm{~kg}$ being accelerated can reach $3500 \mathrm{~m} / \mathrm{sec}$ (with roughly $15 \%$ increase in coil energy or about $1.5 \mathrm{MJ} / \mathrm{stage}$ ), but the maximum temperature is beyond the melting point. The amount of mass melted is roughly 700 grams (thickness of $2 \mathrm{~mm}$ with an axial extent of 20 $\mathrm{cm}$ ). Although this mass is relatively large, most of the melting in a particular length of armature occurs after that length has done its part in pushing of the armature. This implies that loss in efficiency might not be significant due to the melting. To test this assumption, a simulation of the above parameters (with fine zoning 
and thermal conduction) was carried out in which the contribution to the armature axial force was turned off once an element reached the melting point. Results of this simulation show a final velocity of $3 \approx 33 \mathrm{~m} / \mathrm{sec}$ compared with $3248 \mathrm{~m} / \mathrm{sec}$. This verifies the assertion that most of the forward going pressure is generated before the element generating the pressure reaches the melting point. Containment of the melted aluminum and effects on the aero-shell and other parts of the launcher need to be studied.

Since the length of launcher is roughly proportional to the square of the muzzle velocity, length can be significantly reduced for muzzle velocities of the order of $2 \mathrm{~km} / \mathrm{sec}$ compared to $3.5 \mathrm{~km} / \mathrm{sec}$. We have run simulations for a 20 meter launcher (270 stages) for the above parameters with $8 \mathrm{~cm}$ coil build and energy grading. Proportional slip with $\alpha=12 \times 10^{-3}$ was used. For a rise length of $14 \mathrm{~cm}$, the final velocity is $1787 \mathrm{~m} /$ $\mathrm{sec}$ and the maximum temperature is $504^{\circ} \mathrm{C}$. With a rise length of $18 \mathrm{~cm}$, the final velocity is slightly changed to $1791 \mathrm{~m} / \mathrm{sec}$ and the maximum temperature is $634^{\circ} \mathrm{C}$. The temperature rise in these simulations includes the effect of muzzle braking, but the radial thickness of armature surface elements is $2 \mathrm{~mm}$ and thus is not sufficient to resolve a skin depth. Resolving a skin depth and including the effect of thermal conduction will result in melting of a small mass of the armature. This mass is expected to be significantly smaller than the $700 \mathrm{~g}$ estimate for the 60 meter launcher. Results of the simulation with $14 \mathrm{~cm}$ rise length are shown in Fig. (5).
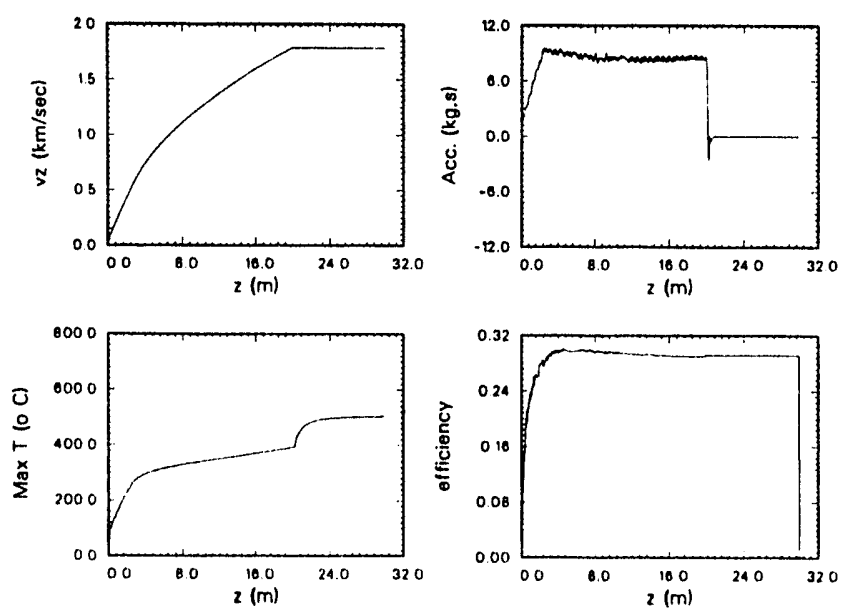

Fig. 5. Simulation results for 20 meter launcher with enrgy grading for the first 30 stages. Slip constant $=12 \times 10^{-3}$ and rise length $=14 \mathrm{~cm}$.

\section{One Element Wound Armature}

A wound armature can help control heating by reducing the current density in the armature. In contrast to the solid armature, the current is distributed uniformly throughout the radial thickness of the armature, not just a skin depth. Apparently by this means armature heating can be controlled well enough to allow one or two current reversals during launch. Current reversal allows operation with flux in the armature which is antiparallel to that in the coils and results in a significant increase in the efficiency. The forward-going force is proportional to efficiency. While current reversal is possible with solid armatures it is not practical because 
of the high current density which results in excessive heating and rapid decay of the flux. To be practical, a wound armature must have enough build and fill-factor for good time constant, small number of turns to keep the voltage low and it must be able to survive the mechanical and electrical stresses during launch.

The simplest armature to model is the single element wound armature in which the armature current density is uniform throughout. The reason for this is that diffusion occurs along the full length, and thus there is no need for slipping in this type of armature. Optimum firing positions and rise length are relatively constant throughout the length of the gun with small variations expected due to coil current profile changes (scaled to the rise length) that result from external circuit parameter variations (coupling to crowbarred coils) and armature current variations ( $\mathrm{L} / \mathrm{R}$ decay and changes due to field reversal).

Since a single element wound armature is much longer than a coil, it is necessary for accurate calculation of mutual inductances, that the armature is subdivided into elements until a convergent value of the inductance is obtained. If the armature is divided into $\mathrm{N}_{\mathrm{a}}$ elements and the coil is divided into $\mathrm{N}_{\mathrm{c}}$ elements, with uniform current in the elements, the mutual inductance can be written as: $M=\frac{1}{N_{c} N_{a}} \sum_{N_{c}} \sum_{N_{a}} M_{i j}$ where $\mathrm{M}_{\mathrm{ij}}$ is the mutual inductance between the ith armature element and jth coil element and is calculated in Slingshot using Lyle's method $^{(7)}$. Convergence of $\mathrm{M}$ for a $40 \mathrm{~cm}$ long armature with $5.5 \mathrm{~cm}$ inner radius and $9.5 \mathrm{~cm}$ outer radius, is attained for $\mathrm{N}_{\mathrm{c}}=1$ and $\mathrm{N}_{\mathrm{a}}=8$. In Fig. (6) we show the mutual inductance between a coil $\left(\mathrm{r}_{\mathrm{i}}=10.5\right.$ $\mathrm{cm}, \mathrm{r}_{\mathrm{o}}=16 \mathrm{~cm}$ and $\left.\Delta \mathrm{Z}=6 \mathrm{~cm}\right)$ and the $40 \mathrm{~cm}$ long armature element $\left(\mathrm{r}_{\mathrm{i}}=5.5 \mathrm{~cm}\right.$ and $\left.\mathrm{r}_{\mathrm{o}}=9.5 \mathrm{~cm}\right)$ vs. the axial separation distance. The width of the nearly flat top of this curve gives an indication of the optimum rise length to be used. Also, as a check on the Slingshot value of the armature self inductance $L_{a}$, the armature is divided into $\mathrm{N}$ equal elements and $\mathrm{L}_{\mathrm{a}}$ is compared to the expression $\frac{1}{N^{2}} \sum_{i} \sum_{J} M_{i j}$, where $\mathrm{M}_{\mathrm{ij}}$ is the mutual inductance between $i$ th and $j$ th elements for $i \neq j$ and the self inductance for $i=j$. As before the mutual inductances are calculated using Lyle's method. The comparison between the two expressions is excellent and gives us confidence in all the Slingshot inductance calculations.

For the one element armature it is straight forward to calculate the maximum possible efficiency for lossless and completely uncoupled coils and lossless armature for cases with or without armature flux. For a coil and armature with self inductances $\mathrm{L}_{c}$ and $\mathrm{L}_{\mathrm{a}}$ and mutual inductance $\mathrm{M}$ (defined per turn) we find, using energy conservation, for the case with no initial armature flux: $\eta_{\max }=k^{2}$, where $\eta_{\max }$ is the maximum possible efficiency (ratio of kinetic energy to input magnetic energy) and $k$ is the coupling coefficient given by: $k=M / \sqrt{L_{c} L_{a}}$. The ratio between maximum coil current to armature current is equal to $\sqrt{x} k$, and the currents are in opposite directions, where $x=L_{c} / L_{a}$. For the case where the armature has an initial flux equal to and 
opposite in sign to coil flux (per turn) we find: $\eta_{\max }=\frac{2 \sqrt{x} k+(x+1) k^{2}}{(1+\sqrt{x} k)^{2}}$ which reduces to $2 k /(1+k)$ for $x=1$. The ratio of armature current to coil current is: $-\frac{(x+\sqrt{x} k)}{1+\sqrt{x} k}$. Even though this calculation is highly idealized, nevertheless it serves to show the importance of using current reversal to establish anti-parallel flux in the armature and shows scaling with armature length. In the following table we list the mutual and self inductance of armatures with different lengths (the coil self inductance for one turn is $\mathrm{L}_{\mathrm{c}}=29 \times 10^{-8} \mathrm{H}$. We also give calculated values for the maximum efficiency and current ratios for the case without armature flux (1) and with armature flux (2):

\begin{tabular}{llllllll} 
& & \multicolumn{3}{c}{ No flux } & \multicolumn{4}{c}{ With flux } \\
Length $(\mathrm{cm})$ & $\mathrm{M}(\mathrm{H}) \times 10^{-8}$ & $\mathrm{~L}_{\mathrm{a}}(\mathrm{H}) \times 10^{-8}$ & $\eta_{1}$ & $\left(\mathrm{I}_{\mathrm{a}} / I_{\mathrm{c}}\right)_{1}$ & $\eta_{2}$ & $\left(\mathrm{I}_{\mathrm{a}} / I_{\mathrm{c}}\right)_{2}$ \\
40.0 & 4.78 & 3.93 & 0.20 & 1.22 & 0.84 & 3.88 \\
30.0 & 5.80 & 4.95 & 0.23 & 1.17 & 0.84 & 3.26 \\
20.0 & 7.18 & 6.68 & 0.27 & 1.08 & 0.83 & 2.59 \\
10.0 & 8.88 & 10.2 & 0.27 & 0.87 & 0.79 & 1.96
\end{tabular}

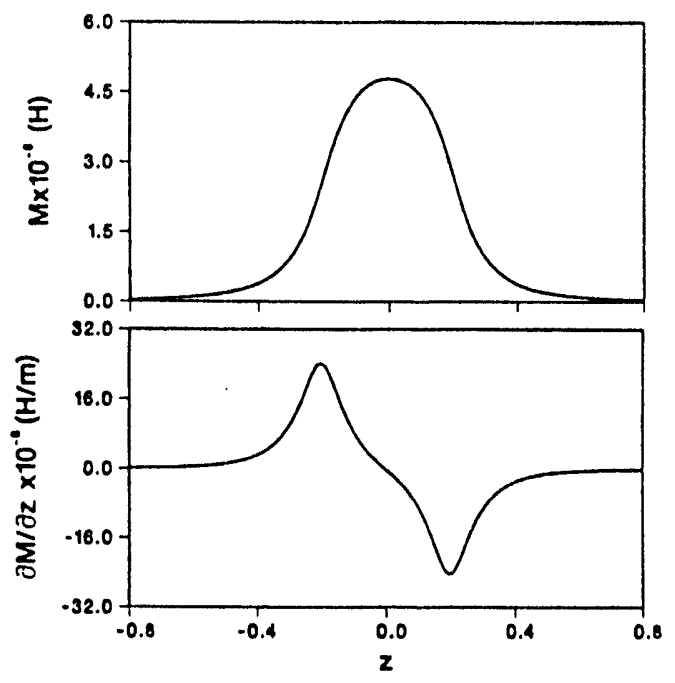

Fig. 6. Mutual inductance and derivative between coil and a single element wound armature.

It is clear from the above table that the longer the armature the smaller the temperature rise will be because of the associated current densities For the simulations we only consider the case of $40 \mathrm{~cm}$ length since that would result in the lowest temperature rise. However, if there is need for larger payload masses or a larger margin of temperature rise can be tolerated, it is possible to use shorter armatures. It is interesting to note that $\eta_{1}$ is not the maximum efficiency when coil-coil coupling is taken into account. Slingshot simulations with no coil or armature resistance give higher efficiencies than in the above table for the case with no flux. This is due to coil-coil coupling. With small coil spacing, field energy is mostly contained within a coil radius, whereas a significant amount of energy is outside a coil radius for a single coil. As coil-coil spacing is increased, the efficiency of Slingshot simulations falls below the values in the above table.

Because of the lower current density in a wound armature and the resulting low temperature rise, it is possible to take advantage of working against armature flux using field reversal. We have run several simulations with the $40 \mathrm{~cm}$ long, one element wound armature. This type of armature results in best performance and lowest temperature rise. Results of a simulation with two field reversals are shown in Fig. (7). This simulation has non-integer number of turns and used a coil with build of $5.5 \mathrm{~cm}$, fill factor of 0.5 , 
and an armature with fill factor of 0.8 . The rise length and firing position were determined by several optimization runs, 100 stages at a time. The velocity after 50 meters of gun reached $3541 \mathrm{~m} / \mathrm{sec}$ with a temperature of $300^{\circ} \mathrm{C}$. In contrast to the solid armature, this is the true temperature rise. The efficiency for this gun is roughly $45 \%$. After 60 meters ( 800 stages) the velocity reaches $3871 \mathrm{~m} / \mathrm{sec}$ and the temperature is $333^{\circ} \mathrm{C}$. The temperature rise due to muzzle braking is insignificant. With the same parameters except for the armature fill factor of 0.6 , the velocity at 55 meters is $3552 \mathrm{~m} / \mathrm{sec}$ at a temperature of $583^{\circ} \mathrm{C}$. If the coil build is increased to $8 \mathrm{~cm}$ at a fill factor of 0.2 (armature fill factor of 0.8 ) the velocity at 55 meters is $3494 \mathrm{~m} / \mathrm{sec}$ and the temperature is $320^{\circ} \mathrm{C}$. It should be noted that in Fig. (7) that there is very large negative spikes in the acceleration at the points of field reversal. This is due to the finite arnount of time it takes the armature current to reverse because of the finite resistivity. By decreasing the energy for the first three stages (to $\mathrm{V}=-10 \mathrm{kV}$ ) after the reversal and delaying the firing positions of these stages by $6 \mathrm{~cm}$, these acceleration spikes were reduced to less than $-4 \mathrm{~kg}$ 's. The overall performance is not affected by this change.

We also ran a simulation for a 20 meter long launcher (270 stages) with a 1-element wound armature of 0.8 fill factor. For a coil build of $8.0 \mathrm{~cm}$ with fill factor of 0.2 , the final velocity is $2079 \mathrm{~m} / \mathrm{sec}$ and the temperature is $173^{\circ} \mathrm{C}$. This simulation had one field reversal after stage 150 with the first three stages after reversal at low energy $(1 \mathrm{kV})$ and with delayed firing positions to minimize the deceleration spike after the reversal. Results of this simulation are shown in Fig. (8). Further improvement of the performance of this launcher is possible by reversing the field at an earlier stage.
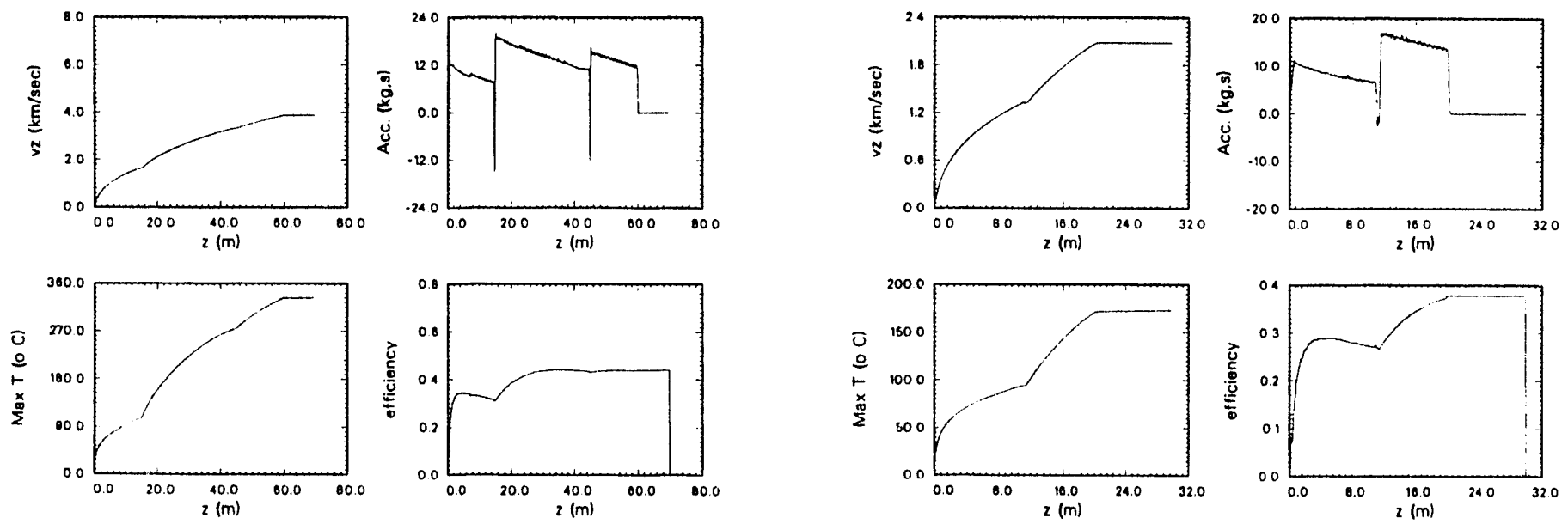

Fig. 7. Simulation of a wound armature in an 800 stage launcher with two field reversals.
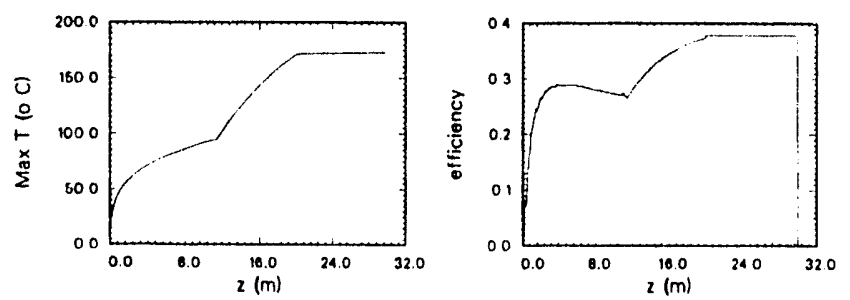

Fig. 8. Results of simulation of a wound armature in a 270 stage launcher with one field reversal.

\section{Multiple Element Wound Armature}

This armature is made of several parallel wound elements stacked axially next to each other. In this case the firing positions would be slipped as for the solid armature case. The advantage of this armature is the 
uniform distribution of the current in the radial direction, thus reducing the temperature rise. We consider the case of a 16 element armature and allow for fractional number of turns in the simulations. For a rise length of $13 \mathrm{~cm}$, proportional slip with $\alpha=5.5 \times 10^{-3}$ and armature fill factor of 0.8 we get a velocity of $3217 \mathrm{~m} / \mathrm{sec}$ at 60 meters with a maximum temperature of $304{ }^{\circ} \mathrm{C}$. This is for coils with $5.5 \mathrm{~cm}$ build and 0.5 fill factor and using energy grading for the first 30 stages as before. For coils of $8.0 \mathrm{~cm}$ build and 0.2 fill factor, with all other parameters the same, we find the velocity at 60 meters is $2973 \mathrm{~m} / \mathrm{sec}$ and the temperature is $265^{\circ} \mathrm{C}$. This performance can be improved with further optimization.

Depending on the maximum allowed temperature rise for this type of armature (depending on the insulation used), it might be possible to allow one field reversal. If this can be done, the performance of this armature can be significantly improved by increasing the slip speed and taking advantage of working against an armature with imbedded flux. With reversed field after stage 140 with a delay of $32 \mathrm{~cm}$ in the firing position for reversed stages, a constant slip speed of $12 \mathrm{~m} / \mathrm{sec}$, coil build of $5.5 \mathrm{~cm}$ with fill factor of 0.5 and the armature fill factor is 0.8 , the velocity and temperature at 60 meters are $3556 \mathrm{~m} / \mathrm{sec}$ and $634^{\circ} \mathrm{C}$. After muzzle braking the maximum temperature reaches $725^{\circ} \mathrm{C}$, which is obviously above the melting temperature for aluminum. With further optimization it might be possible to reduce the temperature rise below melting.

\section{Sensitivity of Performance to Timing of Coil Firing and Other Perturbations}

With any complex system it is expected that there will be small deviations from modeled behavior. In a multicomponent system such as an induction coil launcher it is possible for small deviations in individual components to integrate to very large deviations that can adversely affect overall system operation. It is thus essential to quantify the effects of such deviations on system performance.

In an electromagnetic launcher velocity perturbations can arise as a result of small errors in measured armature positions or jitter in the firing system. In this section we consider the effects of such perturbations on the overall performance of an electromagnetic launcher under normal operating conditions. Fault scenarios are not considered in this report.

Before considering effects of perturbations in launchers where the firing times are determined by real time armature position, it is useful to consider an example in which small velocity perturbations result in an exponential deterioration of the performance. Such an example is a launcher in which the firing times are predetermined. To do this we assume that firing times are set for an optimized case that gives an average acceleration $a_{0}$. For this optimum case the velocity and distance are given by: $v_{1}(t)=v_{0}+a_{0} t$ and $s_{1}(t)=v_{0} t+$ $1 / 2 a_{0} t^{2}$, where $v_{0}$ is the initial velocity at the stage where we begin analysis. Now consider a perturbed case where the initial velocity is $v_{0}+\delta v$. Since the first case was optimized, it is reasonable to assume that the acceleration in the perturbed case can be approximated by: $a_{2}(t)=a_{0}-\alpha\left|s_{2}(t)-s_{1}(t)\right|$, that is the perturbation 
in acceleration is just proportional to the distance of misfire. The constant $\alpha$ can be estimated based on results of simulations. The equations of motion for the armature in this case are:

$$
\frac{d v_{2}}{d t}=a_{o}-\alpha\left|s_{1}(t)-s_{2}(t)\right| \quad \frac{d s_{2}}{d t}=v_{2}
$$

with initial conditions: $s_{2}(0)=0$ and $v_{2}(0)=v_{0}+\delta v$ and $s_{1}(t)$ given above. If $\delta v<0$ then $s_{1}(t)>s_{2}(t)$ and the solution is given by: $\quad v_{2}(t)=v_{o}+a_{o} t+\delta v \cosh (\sqrt{\alpha} t)$

If $\delta v>0$, the solution is found to be:

$$
v_{2}(t)=\left\{\begin{array}{cc}
v_{o}+a_{o} t+\delta v \cos (\sqrt{\alpha} t) & t \leq \frac{\pi}{\sqrt{\alpha}} \\
o r & t \geq \frac{\pi}{\sqrt{\alpha}} \\
v_{o}+a_{o} t-\delta v \cosh (\sqrt{\alpha} t-\pi) &
\end{array}\right.
$$

Thus for both positive and negative perturbations the end result is exponential degradation in the velocity. A rough order of magnitude estimate of the parameter $\alpha$ is obtained by assuming that the acceleration is degraded by $2 \%$ for $\Delta s=2 \mathrm{~cm}$, where $\Delta s$ is deviation from optimum firing position. For $a_{0}=10 \mathrm{~kg}$ 's, we find $\alpha=1 \times 1 u^{5}$ $\mathrm{sec}^{-2}$ and thus for a time duration of $10 \mathrm{~ms}$ we find the velocity perturbation would grows by a factor of 24 . This clearly shows that it is impractical to pre-determine the firing times based on an optimized simulation.

For practical launchers, coil firing must be based on measured armature position. This is what is done in launcher experiments at Sandia ${ }^{(8)}$. To estimate the effects of small rors in measured armature position and jitter in firing circuits, we consider Slingshot simulations in which the firing position is modified as follows:

$Z_{\text {fire }} \rightarrow Z_{\text {fire }}+2 v_{z} \delta t(0.5-R)$

where $R$ is a uniform random number between 0 and $1, v_{z}$ is the projectile velocity at time of fire, $\delta t$ is the firing time jitter and $Z_{\text {fire }}$ on the RHS of the above equation is the normal Slingshot firing position. We ran simulations for the solid armature case with coil build of $5.5 \mathrm{~cm}$ and using energy grading. The baseline velocity and temperature at 60 meters for this simulation were $3258 \mathrm{~m} / \mathrm{sec}$ and $671^{\circ} \mathrm{C}$ respectively and are shown in Fig. (4). For $\delta t=2 \mu-\sec$ the velocity and temperature at 60 meters are $3256 \mathrm{~m} / \mathrm{sec}$ and $686{ }^{\circ} \mathrm{C}$ respectively. If $\delta \mathrm{t}$ is increased to $10 \mu$-secs the velocity and temperature at 60 meters are $3234 \mathrm{~m} / \mathrm{sec}$ and 1021 ${ }^{\circ} \mathrm{C}$. The small effect of firing position perturbation on the final velocity is expected based on the relatively weak dependence of acceleration on rise length and the small ratio of the maximum perturbation to rise length. At $\delta t=10 \mu$-secs and $v_{z}=3 \mathrm{~km} / \mathrm{sec}$, the maximum firing position perturbation is $3 \mathrm{~cm}$, which is much smaller than a rise length (for the simulations a rise length of $15 \mathrm{~cm}$ is used). Simulation results show that acceleration 
recovers to normal values when the firing position is corrected, that is, the perturbation causes only a temporary change in the acceleration which is localized to the coil (or a few coils) causing the perturbation.

In a real launcher, the armature position would be determined by a laser ranger or some other means which should be accurate to within a few millimeters. At high velocities the main firing position perturbations result from jitter in firing and coil switching circuits. Reasonable values for the jitter would be about $\pm 1 \mu-\mathrm{sec}$, which implies that this mechanism for firing position perturbations will not have any significant effects on the launcher performance for rise lengths of interest. For small rise lengths however, this effect can have significant effects on launcher performance.

\section{Summary of Results}

In this report we have considered the performance of an electromagnetic launcher of $20 \mathrm{~cm}$ bore diameter for several types of armatures. This was done for an 800 stage launcher (60 meters long) at an energy of 1.28 $\mathrm{MJ} / \mathrm{stage}$ with a total accelerated mass of $60 \mathrm{~kg}$. The forward going pressure is of the order of $2 \mathrm{kBars}$. The armature types considered are: Solid cylindrical shell, one element wound and a 16 element wound armature. All armatures are made of 7075-T73 aluminum at room temperature.

The best performance was obtained with the one element wound armature. With two field reversals the average efficiency for this armature ( $40 \mathrm{~cm}$ long) is about $45 \%$ and a velocity of $3.5 \mathrm{~km} / \mathrm{sec}$ can be achieved in 50 meters. The temperature rise is less than $300^{\circ} \mathrm{C}$. This result is for a coil of $5.5 \mathrm{~cm}$ build. With $8.0 \mathrm{~cm}$ coil build, a final velocity of $3.5 \mathrm{~km} / \mathrm{sec}$ can be achieved after 55 meters of launcher length.

Slingshot simulations with a room temperature solid armature achieved $3.3 \mathrm{~km} / \mathrm{sec}$ after 60 meters of launcher length ( 800 stages) for coils with $5.5 \mathrm{~cm}$ build. For coils with $8.0 \mathrm{~cm}$ build the velocity at 60 meters is $3.0 \mathrm{~km} / \mathrm{sec}$. In all simulations with a solid armature, even when effects of radial thermal conduction are included, a certain amount of armature material melts. The amount of melted material is estimated to be about 700 grams to reach a velocity of $3.3 \mathrm{~km} / \mathrm{sec}$. It is shown that most melting occurs after contribution to the forward going pressure is made. Thus melting has a minor effect on the overall performance of the launcher. Containment and or flow of the molten armature material and the effect on the launcher system is a problem that needs to be studied.

Simulations of a 16-element wound armature were also performed. Each element has an axial extent of 2.5 $\mathrm{cm}$ and $4 \mathrm{~cm}$ radial thickness with uniform current density. Without field reversal, this armature (fill factor of 0.8 ) can achieve $3.2 \mathrm{~km} / \mathrm{sec}$ for $5.5 \mathrm{~cm}$ coil build and $3.0 \mathrm{~km} / \mathrm{sec}$ for $8.0 \mathrm{~cm}$ coil build, which is very similar to the solid armature result. The maximum temperature rise, which occurs in the element closest to the breech, is below $300^{\circ} \mathrm{C}$. 
With one field reversal, the 16-element wound armature can reach a velocity of $3.5 \mathrm{~km} / \mathrm{sec}$ after 800 stages for coils with $5.5 \mathrm{~cm}$ build. However, the maximum temperature is $630^{\circ} \mathrm{C}$. With further optimization we expect that this temperature can be reduced somewhat. The possibility of having one field reversal for this type of armature will depend on the type of insulation used and the maximum allowed temperature rise. The results for different types of armatures are summarized in Table I.

Sensitivity of launcher performance to small perturbations in the firing position was considered for solid armatures. The results are expected to be the same for all armature types. Slingshot simulations with a $\pm 10 \mu-$ sec random jitter in the coil firing times resulted in only $0.7 \%$ reduction in the final velocity after 800 stages although the temperature rise was significant. With a $\pm 2 \mu-\mathrm{sec}$ jitter, the reduction in velocity is less than $0.1 \%$ and the additional temperature rise is only $2 \%$. The expected jitter is of the order of $\pm 1 \mu$-sec, thus the effect of coil firing time jitter on launcher performance is expected to be insignificant.

Table I. Velocity and Temperature Rise for Three Types of Armatures

\begin{tabular}{|c|c|c|c|c|c|}
\hline Armature & $\begin{array}{l}20 \text { meters } \\
270 \text { stages } \\
8.0 \mathrm{~cm} \text { build }\end{array}$ & $\begin{array}{l}50 \text { meters } \\
665 \text { stages } \\
5.5 \mathrm{~cm} \text { build }\end{array}$ & $\begin{array}{l}55 \text { meters } \\
730 \text { stages } \\
8.0 \mathrm{~cm} \text { build }\end{array}$ & $\begin{array}{l}60 \text { meters } \\
800 \text { stages } \\
5.5 \mathrm{~cm} \text { build }\end{array}$ & $\begin{array}{l}60 \text { meters } \\
800 \text { stages } \\
8.0 \mathrm{~cm} \text { build }\end{array}$ \\
\hline Solid & $1.8 \mathrm{~km} / \mathrm{sec}$ & & & $\begin{array}{l}3.3 \mathrm{~km} / \mathrm{sec} \\
\text { Some melting }\end{array}$ & $\begin{array}{l}3.0 \mathrm{~km} / \mathrm{sec} \\
\text { Some melting }\end{array}$ \\
\hline $\begin{array}{l}\text { 1-element } \\
\text { wound } \\
0.8 \text { fill factor }\end{array}$ & $\begin{array}{l}2.1 \mathrm{~km} / \mathrm{sec} \\
173^{\circ} \mathrm{C}\end{array}$ & $\begin{array}{l}3.5 \mathrm{~km} / \mathrm{sec} \\
300{ }^{\circ} \mathrm{C}\end{array}$ & $\begin{array}{l}3.5 \mathrm{~km} / \mathrm{sec} \\
320^{\circ} \mathrm{C}\end{array}$ & $\begin{array}{l}3.9 \mathrm{~km} / \mathrm{sec} \\
333^{\circ} \mathrm{C}\end{array}$ & \\
\hline $\begin{array}{l}\text { T6-element } \\
\text { wound } \\
0.8 \text { fill factor }\end{array}$ & & & & $\begin{array}{l}3.2 \mathrm{~km} / \mathrm{sec} \\
304^{\circ} \mathrm{C}\end{array}$ & $\begin{array}{c}3.0 \mathrm{~km} / \mathrm{sec} \\
265^{\circ} \mathrm{C}\end{array}$ \\
\hline
\end{tabular}

\section{References}

1- M. Cowan, M. M. Widner, E. C. Cnare, B. W. Duggin, R. J. Kaye and J. R. Freeman, "Exploratory Development of the Reconnection Launcher 1986-1990", IEEE Transactions on Magnetics, Vol. 27, No. 1, January 1991. 
2- R. J. Kaye, E. L. Brawley, B. W. Duggin, E. C. Cnare, D. C. Rovang and M. W. Widner, "Design and Performance of a Multi-Stage Cylindrical Reconnection Launcher", IEEE Transactions on Magnetics, Vol. 27, No. 1, January 1991.

3- M. M. Widner, "WARP-10: A Numerical Simulation Model for the Cylindrical Reconnection launcher”, IEEE Transactions on Magnetics, Vol. 27, No. 1, January 1991.

4- M. Cowan and I. R. Shokair, "Advantages of a Wound Armature", Sandia Internal memo, March 15, 1993

5- The Slingshot code was written by B. M. Marder and solves the same circuit equations as the WARP-10 code.

6- I. R. Shokair, "Sensitivity of Coil Launcher Performance to Small Variations", Sandia Internal memo, August 3, 1992.

7- F. W. Grover, “Inductance Calculations”, Dover Publications, Inc. 1946.

8- R. J. Kaye, Private communications.

\section{Acknowledgments}

This work was supported by the Department of Energy under Contract No. DE-AC04-94AL85000.

\section{DISCLAIMER}

This report was prepared as an account of work sponsored by an agency of the United States Government. Neither the United States Government nor any agency thereof, nor any of their employees, makes any warranty, express or implied, or assumes any legal liability or responsibility for the accuracy, completeness, or usefulness of any information, apparatus, product, or process disclosed, or represents that its use would not infringe privately owned rights. Reference herein to any specific commercial product, process, or service by trade name, trademark, manufacturer, or otherwise does not necessarily constitute or imply its endorsement, recommendation, or favoring by the United States Government or any agency thereof. The views and opinions of authors expressed herein do not necessarily state or reflect those of the United States Government or any agency thereof. 

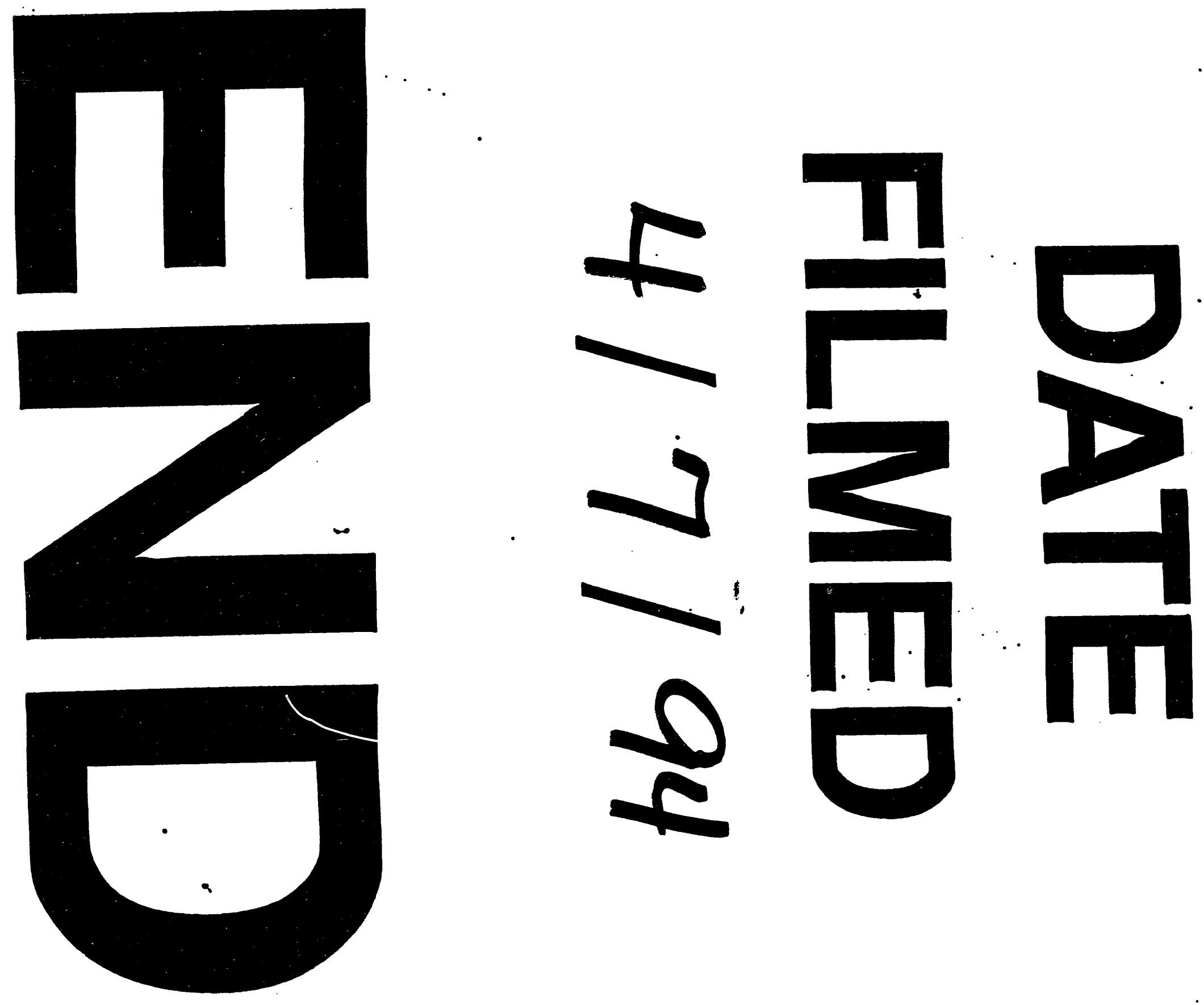


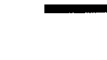

